\title{
Patient-Centered Care for Muslim Women: Provider and Patient Perspectives
}

\author{
Memoona Hasnain, M.D., MHPE, Ph.D., ${ }^{1}$ Karen J. Connell, M.S., \\ Usha Menon, Ph.D., R.N., ${ }^{2}$ and Patrick A. Tranmer, M.D., M.P.H.'
}

\begin{abstract}
\end{abstract}
Objective: The purpose of this study was twofold: (1) to address the gap in existing literature regarding provider perspectives about provision of high-quality, culturally appropriate, patient-centered care to Muslim women in the United States and (2) to explore congruence between provider and patient perceptions regarding barriers to and recommendations for providing such care.

Methods: Using a cross-sectional study design, a written survey was administered to a convenience sample of healthcare providers $(n=80)$ and Muslim women $(n=27)$.

Results: There was considerable congruence among patients and providers regarding healthcare needs of Muslim women. A majority $(83.3 \%)$ of responding providers reported encountering challenges while providing care to Muslim women. A majority (93.8\%) of responding patients reported that their healthcare provider did not understand their religious or cultural needs. Providers and patients outlined similar barriers/challenges and recommendations. Key challenges included lack of providers' understanding of patients' religious and cultural beliefs; language-related patient-provider communication barriers; patients' modesty needs; patients' lack of understanding of disease processes and the healthcare system; patients' lack of trust and suspicion about the healthcare system, including providers; and system-related barriers. Key recommendations included provider education about basic religious and cultural beliefs of Muslim patients, provider training regarding facilitation of a collaborative patient-provider relationship, addressing language-related communication barriers, and patient education about disease processes and preventive healthcare.

Conclusions: Both providers and patients identify significant barriers to the provision of culturally appropriate care to Muslim women. Improving care would require a flexible and collaborative care model that respects and accommodates the needs of patients, provides opportunities for training providers and educating patients, and makes necessary adjustments in the healthcare system. The findings of this study can guide future research aimed at ensuring high-quality, culturally appropriate, patient-centered healthcare for Muslim women in the United States and other western countries.

\section{Introduction}

T HE INCREASING DIVERSITY of the United States population has implications for all aspects of healthcare delivery. Healthcare disparities among cultural groups are well documented; contributing factors include differences in access to and use of services, quality of care and services rendered, and perceived satisfaction with the healthcare provided. Provision of high-quality, culturally appropriate care requires attention to the diversity of patient beliefs, as well as perceptions and expectations across cultural groups. ${ }^{1-7}$ Vulnerable popula- tions, such as low-income individuals, uninsured persons, and immigrants, face even greater barriers to high-quality care. $^{8}$

Meeting the unique cultural and religious needs of Muslim patients has been a subject of considerable recent interest in the United States and other western countries. ${ }^{9-22}$ The increasing number of Muslims in the United States makes it relevant and timely to understand and address barriers to quality care for this population. Although estimates vary widely, the number of Muslims in the United States is estimated to be 6 million ( $47 \%$ women) and growing. ${ }^{23,24}$ It is

\footnotetext{
${ }^{1}$ Department of Family Medicine, College of Medicine, University of Illinois at Chicago, Chicago, Illinois.

${ }^{2}$ College of Nursing and Health Innovation, Arizona State University, Phoenix, Arizona.
} 
projected that Muslims will be the second largest religious group in the United States. ${ }^{25}$ Projected increases are due mainly to migration but also to religious conversion.

Apart from African American Muslims who are indigenous to the United States and comprise the largest number of American Muslims, immigrant Muslims are ethnically extremely varied, coming from virtually every country where Muslims live. The single largest group of Muslim immigrants in the United States is from South Asian countries (33\%), followed by the Middle Eastern countries (25\%). ${ }^{26}$ Muslims, regardless of their country of origin and ethnic and cultural diversity, have in common a religious thread that impacts the entire spectrum of their health-related beliefs and practices, including but not limited to sexual norms, reproductive health, and maternal and child health issues. ${ }^{12,22,27-34}$ Muslim women's specific religious and cultural needs, such as the need for same-gender providers, dietary restrictions, special needs during fasting, and personal hygiene issues related to daily prayers, require consideration and accommodation by healthcare providers. Lack of providers' attention to these needs compromises the provision of quality care and contributes to Muslim women's reluctance to seek and use healthcare services, including critically important services for prenatal care, labor and delivery, postdelivery consultation, care of newborns, contraception, and cancer screening. ${ }^{14,17,35}$ These problems are compounded for immigrant Muslim women who, upon coming to western countries encounter a different culture, language, and healthcare system.

Although researchers in the United States have acknowledged the importance of the need for healthcare professionals to be nonjudgmental and respectful of the traditions of other cultures, ${ }^{36-38}$ the American healthcare system is not designed to accommodate Muslim women's religious and cultural needs. A comprehensive review of the literature focusing on health problems of immigrant women ${ }^{39}$ shows that there is a paucity of studies concerning the barriers to quality care for Muslim women. Those few studies that have examined Muslim women's perceptions of the barriers they face in receiving quality care indicate that religious and cultural beliefs, such as the value placed on modesty, and the lack of providers' accommodation of these beliefs contribute to Muslim women's reluctance to seek healthcare. ${ }^{10,11,14,17}$ The manner and degree to which Islamic beliefs and customs can influence healthcare use by immigrant Muslim women also has been noted, highlighting the need for informing patients' health-related knowledge and practices within a religious and sociocultural context.

Existing studies suffer from several limitations, including (1) grouping Muslim women within other cultural groups, such as Asian and Middle Eastern, (2) wide variation in study samples and lack of standardized operational definitions of beliefs and outcome variables, making it difficult to compare findings across studies, (3) lack of empirical studies and scientific data specific to interventional research directed at appropriate and timely healthcare use by Muslim women, and (4) a glaring paucity of research exploring healthcare providers' perceptions about the challenges they face in providing quality care to Muslim women and how these challenges can be overcome.

The purpose of this article is to present the results of an exploratory study that examined the perspectives of both healthcare providers and patients regarding major challenges to and recommendations for the provision of culturally ap- propriate, patient-centered care for Muslim women and studied the congruence between provider and patient perspectives. Of particular importance for this study was exploring the provider perspectives, which has not been the focus of previous research on this subject.

\section{Materials and Methods}

\section{Setting and participants}

Convenience sample of Muslim women and healthcare providers participating in a 2-day conference titled, PatientCentered Health care for Muslim Women in the United States, held in Chicago, Illinois. ${ }^{40}$ Eighty of $90(89 \%)$ providers and 27 of $33(82 \%)$ Muslim women participants returned completed questionnaires. Because of the size and selection method of the study sample, the study is mainly exploratory in nature.

\section{Research questions}

1. Do providers and patients differ in their perceptions about Muslim women's health needs?

2. What challenges do providers and patients face concerning culturally appropriate healthcare for Muslim women?

3. What specific changes can help ensure provision of culturally appropriate, patient-centered care to Muslim women?

\section{Study design and data collection}

Using a cross-sectional design, a self-administered, written survey study was conducted. Participants completed a University of Illinois at Chicago Institutional Review Boardapproved written questionnaire designed to query healthcare providers' and Muslim women's perceptions regarding barriers impeding the provision of quality care to Muslim women. The questionnaire had provider and patient versions. Both versions of the questionnaire included demographic questions, a seven-item attitudinal scale (developed for this study) regarding Muslim women's health needs, and four open-ended questions that probed participants' experiences related to the provision of healthcare for Muslim women, their perceptions about major barriers, and recommendations for improving the quality of care for the patient group under study.

\section{Attitudinal scale items.}

1. Health needs of Muslim women are different from those of other cultural/ethnic groups.

2. Healthcare providers should take into account the religious or cultural beliefs of Muslim women.

3. Providers need to learn more about Muslim women's religious or cultural beliefs to take care of their health needs.

4. Muslim women have the right to be treated by healthcare providers according to their religious beliefs.

5. It is important for Muslim women not to be examined by male providers.

6. Muslim women's need for modesty (e.g., not to have a pelvic or breast examination by a male provider) is justified.

7. Muslim women face barriers to care because of their religious beliefs. 


\section{Open-ended questions: Provider version.}

1. Briefly describe an experience with a Muslim woman patient that you feel was positive. Do your best to make clear what you think made it such a positive experience.

2. Briefly describe an experience with a Muslim woman patient that you feel was negative. As you did above, explain as clearly as you can what made it such a negative experience.

3. In your experience, when providing care to Muslim women, what is the greatest challenge? (List more than one if needed.)

4. Please list three ways to ensure provision of culturally sensitive healthcare to Muslim women.

\section{Open-ended questions: Patient version.}

1. Briefly describe an experience with a healthcare provider (e.g., physician or nurse) or system (e.g., clinic, emergency room) that you feel was positive. Do your best to make clear what you think made it such a positive experience.

2. Briefly describe an experience with a healthcare provider or system that you feel was negative. As you did above, explain as clearly as you can what made it such a negative experience.

3. In your experience, what factor(s) make it most difficult for you to obtain quality healthcare? (List more than one if needed.)

4. Please list three ways to ensure provision of culturally sensitive healthcare to Muslim women.

Table 1. Provider Demographics $(N=80)$

\begin{tabular}{lcc}
\hline & $\mathrm{n}$ & $\%$ \\
\hline Male & 14 & 17.5 \\
Female & 66 & 82.5 \\
Religious affiliation & & \\
$\quad$ Muslim & 30 & 38.0 \\
Christian & 30 & 38.0 \\
Jewish & 1 & 1.3 \\
No religion & 7 & 8.9 \\
Other & 11 & 13.8 \\
Ethnicity & & \\
African American & 6 & 7.6 \\
Asian/Pacific Islander & 28 & 35.5 \\
Hispanic or Latin American & 2 & 2.5 \\
White & 34 & 43 \\
Middle Eastern or Arab & 5 & 6.3 \\
Other & 4 & 5.1 \\
Country of birth & & \\
Foreign born & 32 & 40 \\
$\quad$ U.S. born & 48 & 60 \\
Primary language & & \\
English & 57 & 71 \\
Other & 23 & 29 \\
Occupation & & \\
Physician including residents & 29 & 36.25 \\
Nurse & 24 & 30 \\
Allied healthcare providers & 24 & 30 \\
Health professions students & 2 & 2.5 \\
Missing & 1 & 1.25 \\
\hline
\end{tabular}

\section{Data analysis}

Quantitative data were analyzed using the Statistical Package for Social Sciences (SPSS) 15.0 for Windows. Descriptive statistics were computed for demographic variables. Internal consistency reliability of the seven-item attitudinal scale was assessed by computing Chronbach's alpha. Chisquare tests were used to examine the extent of agreement between patients and providers regarding statements pertaining to healthcare needs of Muslim women. Content analysis methodology ${ }^{41}$ was used to code and develop themes from the qualitative data. Given the exploratory nature of the study, descriptive statistics are intended to portray trends and do not indicate statistical significance or generalizability.

\section{Results}

\section{Participant demographics}

Provider demographics $(n=80)$. The providers included 29 physicians (36.25\%), 24 nurses (30\%), 24 allied healthcare providers $(30 \%)$, and 2 health professional students $(2.5 \%)$.

Table 2. Patient Demographics $(N=27)$

\begin{tabular}{|c|c|c|}
\hline & $\mathrm{n}$ & $\%$ \\
\hline $\begin{array}{l}\text { Religious affiliation } \\
\text { Islam }\end{array}$ & 27 & 100 \\
\hline \multicolumn{3}{|l|}{ Gender } \\
\hline Female & 27 & 100 \\
\hline \multicolumn{3}{|l|}{ Ethnicity } \\
\hline Asian/Pacific Islander & 24 & 88.9 \\
\hline White or Caucasian & 1 & 3.7 \\
\hline Middle Eastern or Arab & 1 & 3.7 \\
\hline Missing & 1 & 3.7 \\
\hline \multicolumn{3}{|l|}{ Country of birth } \\
\hline Foreign born & 16 & 59.3 \\
\hline U.S. born & 11 & 40.7 \\
\hline \multicolumn{3}{|c|}{ Length of residence in U.S. (for foreign born) } \\
\hline Less than a year & 1 & 3.7 \\
\hline $1-5$ years & 2 & 7.4 \\
\hline $6-10$ years & 3 & 11.1 \\
\hline More than 10 years & 10 & 37 \\
\hline Missing & 11 & 40.8 \\
\hline \multicolumn{3}{|l|}{ Primary language } \\
\hline Arabic & 2 & 7.4 \\
\hline English & 18 & 66.7 \\
\hline Urdu & 7 & 25.9 \\
\hline \multicolumn{3}{|l|}{ Occupation } \\
\hline Physician (nonpracticing) & 1 & 3.7 \\
\hline Educator & 2 & 7.4 \\
\hline Student & 20 & 74.1 \\
\hline Other & 4 & 14.8 \\
\hline \multicolumn{3}{|c|}{ Highest level of formal education attained } \\
\hline Less than high school graduate & 1 & 4.5 \\
\hline High school graduate & 1 & 4.5 \\
\hline Some college & 6 & 27.3 \\
\hline College graduate & 6 & 27.3 \\
\hline Professional training & 8 & 36.4 \\
\hline \multicolumn{3}{|l|}{ Marital status } \\
\hline Married & 5 & 21.7 \\
\hline Separated or divorced & 0 & 0 \\
\hline Widowed & 0 & 0 \\
\hline Never married & 18 & 78.3 \\
\hline
\end{tabular}


Table 3. Congruence Between Attitudes of Providers and Patients Regarding Health Needs of Muslim Women

\begin{tabular}{|c|c|c|c|c|c|}
\hline & & $\begin{array}{c}\text { Agree/strongly } \\
\text { agree }\end{array}$ & $\begin{array}{c}\text { Disagree/strongly } \\
\text { disagree }\end{array}$ & chi-square & $\mathrm{p}$ value \\
\hline Health needs of Muslim women & Provider & 52 & 23 & & \\
\hline $\begin{array}{l}\text { are different from those of other } \\
\text { cultural/ethnic groups. }\end{array}$ & Patient & 19 & 4 & 1.55 & 0.164 \\
\hline Healthcare providers should take into & Provider & 75 & 1 & & \\
\hline $\begin{array}{l}\text { account the religious or cultural } \\
\text { beliefs of Muslim women. }\end{array}$ & Patient & 25 & 2 & 2.61 & 0.167 \\
\hline Providers need to learn more about & Provider & 76 & 1 & & \\
\hline $\begin{array}{l}\text { Muslim women's religious or cultural } \\
\text { beliefs to take care of their health needs. }\end{array}$ & Patient & 25 & 1 & 0.66 & 0.443 \\
\hline Muslim women have the right to be & Provider & 74 & 1 & & \\
\hline $\begin{array}{l}\text { treated by healthcare providers according } \\
\text { to their religious beliefs. }\end{array}$ & Patient & 24 & 2 & 2.71 & 0.162 \\
\hline It is important for Muslim women not to & Provider & 54 & 9 & 0.55 & 0.458 \\
\hline be examined by male providers. & Patient & 19 & 5 & & \\
\hline Muslim women's need for modesty & Provider & 63 & 5 & 1.94 & 0.163 \\
\hline $\begin{array}{l}\text { (e.g., not to have a pelvic or breast } \\
\text { examination by a male provider) is justified. }\end{array}$ & Patient & 25 & 0 & & \\
\hline Muslim women face barriers to care & Provider & 64 & 11 & & \\
\hline because of their religious beliefs. & Patient & 18 & 6 & 1.36 & 0.243 \\
\hline
\end{tabular}

There were 14 males (17.5\%) and 66 females (82.5\%). Table 1 summarizes provider demographics.

Patient demographics $(n=27)$. The patients in our sample were all Muslim females. A majority, 24 (88.9\%), were Asian, and 1 each (3.7\%) were Caucasian and Arab. About half, 16 (59.3\%), were foreign born, and a majority, 20 (74.1\%), were college or professional students. Eighteen (78.3\%) were never married. Table 2 summarizes patient demographics.

\section{Patient and provider attitudes about healthcare needs of Muslim women}

The internal consistency analysis of the seven items included in the attitudinal scale yielded a Chronbach's alpha of 0.64 . The seven items were independently analyzed using chisquare tests to assess congruence between provider and patient attitudes about the health needs of Muslim women. Providers and patients were largely congruent in their views (Table 3).

\section{Extent of provider and patient challenges}

Of providers of care to Muslim women, $83.3 \%$ reported they had encountered challenges while providing care to Muslim women, and $93.8 \%$ of patients reported that at a previous visit, the healthcare provider did not understand their religious or cultural needs.

\section{Provider and patient perceptions of factors contributing to positive experiences}

Providers. Provider participants were asked to briefly describe an experience with a Muslim woman patient that they felt was positive, along with clarification of what they thought made it so. Fifty-three of eighty (66.25\%) providers responded to the question. Eight (15.09\%) respondents stated they had never had any positive experience with a Muslim woman patient. Two (3.77\%) had never provided care to a Muslim female patient. Of 60 comments made, 55 (91.66\%) were classified in six major categories; $5(8.19 \%)$ comments were not classified because of lack of clarity.

1. Provider communication skills: willingness to listen and give time to the patient, explain and answer questions

2. Provider attitudes: considerate, compassionate, respectful, eliciting and accommodating specific patient needs and preferences

3. Provider gender/ethnicity/religion: same gender, ethnicity, and/or religion

4. Patient communication skills: ability to communicate well and explain needs to the provider

5. Patient attitudes: positive, respectful

Selected provider responses included:

"Awkward at first, but listening and showing that I care and wanted to help was helpful."

"Understanding the patient's culture and beliefs helped me understand her barriers to care so that we could work together for solutions."

"My patient appreciated the knowledge I had on dietary recommendations I made based on Islamic restrictions. Patient was receptive to information ... was keen on assimilating info on American culture and healthcare recommendations."

Patients. Patient participants were asked to briefly describe an experience with a healthcare provider (e.g., physician or nurse) or system (e.g., clinic, emergency room) that they felt was positive along with clarification of what they thought made it so. Twenty-two of $27(81.5 \%)$ patients made 33 comments in response to the above question. All (100\%) comments were classified in one of six major categories.

1. Provider communication skills: willingness to listen and give time to the patient, explain and answer questions, build trust 
2. Provider attitudes: considerate, compassionate, respectful, eliciting and accommodating specific patient needs and preferences

3. Provider competence: ability to provide good care

4. Provider gender/religion: same gender, ethnicity, and/ or religion

5. Provider availability: outside of routine office hours

6. Patient communication skills: ability to communicate well and explain needs to the provider

Selected patient responses:

"I had an experience with a neurologist that really changed my perspective of doctors... he allowed me to speak and clarify any of his questions. Rather than running the meeting with closed-minded questions, he asked only open-ended questions. After discussing my medication and treatment, he went through my normal day's life. We discussed my diet and recommendations that can improve my health. We sat and laughed very comfortably without any pressure to leave. Our conversation made up the majority of my appointment, and the physical consultation lasted only for 10-15 minutes."

"While experiencing jaw pain, I went to an oral surgeon. He respected my request for a family member to be in the room with me and was very respectful of my beliefs. He told me why he was doing what he was doing and asked me if I was okay with it."

"The doctor (female) was listening to me. ... she took my personal hesitations and preferences into account. She explained insurance coverage details."

"Although my provider is not of my background nor has my religious affiliation, she is a provider who clearly provides culturally appropriate healthcare."

"... I had to go through labor and experienced very helping, excellent healthcare as far as nursing care is concerned. The nurse attending me was very helpful and very efficient. I really like the warmth and willingness to do her job, regardless of ethnicity of the patient."

Table 4 presents descriptive statistics for the major themes that emerged from content analysis of provider and patientreported key factors that contribute to positive experiences in provision of care to Muslim women.

\section{Provider and patient perceptions of factors contributing to negative experiences}

Providers. Participants were asked to briefly describe an experience with a Muslim woman patient that they felt was

Table 4. Major Themes and Frequency of Provider and Patient-Reported Key Factors Contributing to Positive Experiences

\begin{tabular}{|c|c|c|}
\hline \multirow[b]{2}{*}{ Themes } & \multicolumn{2}{|c|}{ Frequency $(\%)$} \\
\hline & $\begin{array}{l}\text { Provider-reported } \\
\text { (55 comments) }\end{array}$ & $\begin{array}{c}\text { Patient-reported } \\
\text { (33 comments) }\end{array}$ \\
\hline $\begin{array}{l}\text { 1. Provider } \\
\text { communication skills }\end{array}$ & $22(36.6)$ & $12(36.4)$ \\
\hline 2. Provider attitudes & $13(21.6)$ & $12(36.4)$ \\
\hline $\begin{array}{l}\text { 3. Provider gender/ } \\
\text { ethnicity/religion }\end{array}$ & $11(18.3)$ & $3(9.1)$ \\
\hline 4. Provider competence & 0 & $3(9.1)$ \\
\hline 5. Provider availability & 0 & $2(6.1)$ \\
\hline $\begin{array}{l}\text { 6. Patient communication } \\
\text { skills }\end{array}$ & $4(6.6)$ & $2(6.1)$ \\
\hline 7. Patient attitudes & $4(6.6)$ & 0 \\
\hline
\end{tabular}

negative along with clarification of what they thought made it so. Fifty-three of $80(66.25 \%)$ providers responded to the above question. Six $(11.32 \%)$ respondents stated they had never had any negative experience with a Muslim woman patient. Two (3.77\%) had never seen a Muslim female patient. Forty-six of $51(90 \%)$ comments made were classified in one of five major categories; 5 comments were not classified because of clarity.

1. Provider communication skills: difficulty understanding patients' religious and cultural needs

2. Provider attitudes: insensitive or disrespectful behavior by some providers

3. Providers' lack of accommodation of patients' cultural beliefs: especially modesty needs; for example, male provider performing intimate examinations without a female nurse or staff member present

4. Patient communication skills: including language difficulties

5. Patient distrust, uncooperativeness: that interfered with establishing rapport with the physician

Selected provider responses:

"... trying to discuss birth control methods with a refugee patient. She refused to speak about it, and I later learned that she had some side effect of using pills or shots, and the use of condoms was culturally unacceptable because it indicates that the man is practicing sexual intercourse outside the family circle."

"I shadowed at a clinic, which provided abortions. An African Muslim woman without adequate interpretation was there for the procedure. She was very uncomfortable (physically, probably emotionally as well).... she was circumcised, which made the procedure more difficult, and since she was in pain and without translation, she was moving a lot, which put her in danger. She had come to the clinic four-five times previously and had been turned away because she had no translator. The doctor decided to perform the abortion because of her persistence."

"... advised a Muslim woman regarding the care of a cancerous growth. She had discounted the care with her primary care physician and oncologist out of lack of support and communication. She wanted to entertain alternative treatments. She sought several healthcare providers, could not afford the treatments. Now is terminally ill. And suspect of the system."

"Due to language barrier for immigrant Muslim women, some of their needs are not taken into account due to lack of time and patience the provider has to offer."

Patients. Participants were asked to briefly describe an experience with a healthcare provider or system that they felt was negative, along with clarification of what they thought had made it so. Twenty-two of $27(81.5 \%)$ patients made 21 comments in response to the above question. One respondent stated that she had never had a negative experience. The rest, 20 of $21(95.23 \%)$ comments were classified in one of four major categories.

1. Provider attitudes: improper or insensitive behavior, for example, personal comments complimenting patient on body parts; arrogance, disrespectful comments

2. Providers' lack of accommodation of cultural beliefs: especially modesty needs, for example, male provider performing intimate examinations without a female nurse or staff member present or making the patient sit 
in a revealing hospital gown for x-ray examination in open waiting area with male patients

3. Provider communication skills: lack of willingness to listen and give time to patient

4. Provider gender/religion: different gender, ethnicity, and/or religion

Selected patient responses:

"One of my earliest experiences in the U.S. as a grad student was disturbing because the doctor made some personal comments; he complimented me on my legs."

"A few years ago, I had to consult a gastroenterologist. My doctor was male, and he did my rectal examination in his office.... there was no female nurse nearby. It left a negative impact on me. Being a woman and above this a Muslim, I felt it was very negative to be treated by a male doctor in the absence of a female."

"... the doctor expressed an arrogant level of superiority, when providing the treatment; really didn't take into account my questions, concerns, and my past medical history."

\section{Provider and patient reported major barriers to providing quality care to Muslim women}

Provider participants were asked to respond to the question: In your experience, when providing care to Muslim women, what is the greatest challenge? Fifty-eight of 80 $(72.5 \%)$ providers made 131 comments in response to the question. One hundred twenty-nine of the 131 comments $(98.5 \%)$ were classified in one of six major categories; 2 comments were not included because of lack of clarity.

1. Lack of providers' understanding of patients' religious and cultural beliefs and practices

2. Language-related patient-provider communication barriers

3. Patients' modesty needs interfering with care provision by male providers

4. Patients' lack of understanding of disease processes as well as the healthcare system

5. System-related barriers, for example, economic and financial issues, including, insurance and transportation issues, resulting in poor access

6. Patients' lack of trust and suspicion about the healthcare system, including providers

Patient participants were asked to respond to the question: In your experience, what factor(s) make it most difficult for you to obtain quality healthcare? Twenty-two of $27(81.5 \%)$ patients made 21 comments in response to the question. Twenty of the 21 comments (95.2\%) were classified in three major categories; one comment was not included because of lack of clarity.

1. Lack of providers' understanding of patients' religious and cultural beliefs and practices

2. System-related barriers, for example, economic and financial issues, including, insurance and transportation issues, resulting in poor access

3. Patients' lack of trust and suspicion about the healthcare system, including providers

Table 5 presents descriptive statistics for the major themes that emerged from content analysis of provider and patient- reported barriers to the provision of quality care to Muslim women.

\section{Key recommendations by providers and patients to ensure quality care for Muslim women}

Both providers and patients were asked to respond to the statement: Please list three ways to ensure provision of culturally appropriate healthcare to Muslim women. Fifty-eight of $80(72.5 \%)$ providers made 172 comments in response to the statement.

Twenty-two of $27(81.5 \%)$ patients made 34 comments in response to the statement.

The comments were classified in four major categories.

1. Addressing lack of providers' understanding of patients' religious and cultural beliefs and practices

a. Provider education about basic religious and cultural beliefs of Muslim patients and their relationship to common health issues

b. Provider training regarding modifications in communication style needed to facilitate a collaborative patient-provider relationship

2. Addressing language-related patient-provider communication barriers

Proposed strategies included:

a. Facilitating opportunities for patients to learn English, matching patients with providers who speak their language

Table 5. Major Themes and Frequency of Provider and Patient-Reported Key Challenges

\begin{tabular}{|c|c|c|}
\hline \multirow[b]{2}{*}{ Themes } & \multicolumn{2}{|c|}{ Frequency $(\%)$} \\
\hline & $\begin{array}{c}\text { Provider-reported } \\
\text { (129 comments) }\end{array}$ & $\begin{array}{l}\text { Patient-reported } \\
\text { (20 comments) }\end{array}$ \\
\hline $\begin{array}{l}\text { 1. Lack of providers' } \\
\text { understanding of } \\
\text { patients' religious } \\
\text { and cultural beliefs } \\
\text { and practices }\end{array}$ & $58(45.0)$ & $2(10)$ \\
\hline $\begin{array}{l}\text { 2. Language-related } \\
\text { patient-provider } \\
\text { communication } \\
\text { barriers }\end{array}$ & $20(15.5)$ & 0 \\
\hline $\begin{array}{l}\text { 3. Patients' modesty } \\
\text { needs interfering } \\
\text { with care provision } \\
\text { by male providers }\end{array}$ & $15(12.0)$ & 0 \\
\hline $\begin{array}{l}\text { 4. Patients' lack of } \\
\text { understanding of disease } \\
\text { processes as well as } \\
\text { the healthcare system }\end{array}$ & $13(10.0)$ & 0 \\
\hline $\begin{array}{l}\text { 5. System-related } \\
\text { barriers, e.g., economic } \\
\text { and financial issues, } \\
\text { including insurance } \\
\text { and transportation issues, } \\
\text { resulting in poor access }\end{array}$ & $12(9.0)$ & $15(75)$ \\
\hline $\begin{array}{l}\text { 6. Patients' lack of trust } \\
\text { and suspicion about } \\
\text { the healthcare system, } \\
\text { including providers }\end{array}$ & $11(8.5)$ & $3(15)$ \\
\hline
\end{tabular}


b. Providing interpreters, providing information to patients in their language

c. Providing opportunities for providers to learn languages commonly used by Muslims

3. Addressing patients' lack of understanding of disease processes and lack of trust and suspicion about the healthcare system, including providers

Proposed strategies included:

Educating Muslim women and their community about western medicine, the healthcare system, and the importance of routine preventive health care

4. Addressing patients' specific needs

Proposed strategies included:

a. Providing female providers for Muslim women patients

b. Separating male and female clinic sections

c. Providing halal food, prayer rooms, cultural services, Muslim chaplains

d. Arranging interdisciplinary teams to take care of Muslim patients

e. Conducting research, including assessing patient satisfaction

Table 6 summarizes the results of the content analysis of provider and patient recommendations to ensure provision of culturally appropriate care for Muslim women.

\section{Discussion}

Religion and culture are closely entwined entities that profoundly influence health-related attitudes, beliefs, and practices. ${ }^{42-44}$ When the religious or cultural needs of patients are not understood, acknowledged, or accommodated, there are significant challenges for both patients and providers that ultimately translate into increased burden on the healthcare system. The purposes of our study were (1) to address the gap

Table 6. Provider and Patient Recommendations for Ensuring Culturally Appropriate Care FOR MUSLIM WOMEN

\begin{tabular}{|c|c|c|}
\hline \multirow[b]{2}{*}{ Theme } & \multicolumn{2}{|c|}{ Frequency (\%) } \\
\hline & $\begin{array}{l}\text { Provider reported } \\
\text { (172 comments) }\end{array}$ & $\begin{array}{l}\text { Patient reported } \\
\text { (34 comments) }\end{array}$ \\
\hline $\begin{array}{l}\text { 1. Addressing lack of } \\
\text { providers' understanding } \\
\text { of patients' religious } \\
\text { and cultural beliefs } \\
\text { and practices }\end{array}$ & $108(62.8)$ & $15(44.11)$ \\
\hline $\begin{array}{l}\text { 2. Addressing } \\
\text { language-related } \\
\text { patient-provider } \\
\text { communication barriers }\end{array}$ & $9(5.23)$ & $2(5.88)$ \\
\hline $\begin{array}{l}\text { 3. Addressing patients' } \\
\text { lack of understanding } \\
\text { of disease processes } \\
\text { and lack of trust and } \\
\text { suspicion about the } \\
\text { healthcare system, } \\
\text { including providers }\end{array}$ & $29(16.86)$ & $13(38.23)$ \\
\hline $\begin{array}{l}\text { 4. Addressing patients' } \\
\text { specific needs }\end{array}$ & $26(15.11)$ & $4(11.76)$ \\
\hline
\end{tabular}

in existing literature regarding provider perspectives on the provision of high-quality, culturally appropriate, patientcentered care to Muslim women in the United States and (2) to explore the congruence between provider and patient perspectives about barriers to and recommendations for providing such care.

The findings of our study shed light on the kinds of difficulties faced by Muslim women and healthcare providers and help with understanding some of the dilemmas faced by each. This study points particularly to the importance of cultural competence and patient-centered care, which are frequently ignored in the design and delivery of healthcare services and in patient-physician communication in general and for underserved and minority patients in particular. ${ }^{8,45-48}$ Our study findings also underscore the importance of involving both patients and providers in a process of collaborative partnership for identifying and addressing barriers to the provision of culturally appropriate care.

The quantitative and qualitative findings of this study indicate that there is similarity in the views of providers and patients regarding Muslim women's healthcare needs. As shown in Table 3, there is significant congruence between providers and patients regarding attitudes toward the health needs of Muslim women. Both providers and consumers tended to agree/strongly agree with each of the statements. The greatest disparity between the groups was for items 1 and 7 . Approximately $44 \%$ of the providers disagreed with the statement: Health needs of Muslim women are different from those of other cultural/ethnic groups, in contrast to $21 \%$ of the patients, and $33 \%$ of the patients disagreed with the statement: Muslim women face barriers to care because of their religious beliefs, in contrast to only $17 \%$ of the providers. Although not statistically significant, the percentage differences may suggest that although providers recognize that the health needs of Muslim women are different from those of other cultural/ethnic groups, Muslim patients see such needs as presenting more barriers to care than do providers.

Considerable congruence also was found between patient and provider perspectives gleaned from the qualitative data, regarding not only the nature of challenges but also the changes that must be made to accommodate the needs of this population. Although study participants identified some patient and healthcare system-related barriers, the bulk of the reported challenges, particularly by providers, were related to providers' lack of understanding of the religious and cultural needs of patients. It is critical to delineate that whereas patients reported that there was a lack of sensitivity to and accommodation of patients' religious needs, providers reported a lack of understanding on their part of Muslim female patients' religious and cultural needs, which in turn prevents them from providing appropriate care. These findings highlight the disconnect between patients and providers despite their similarity in views. Clearly, strategies to enable patients and providers to more directly communicate are needed. Effective communication has been shown to improve patient satisfaction, adherence to treatment, and disease treatment outcomes. ${ }^{49,50}$

Table 6 indicates both similarities and differences between providers and patients regarding recommendations for ensuring culturally appropriate care for Muslim women. Relatively small percentages $(5 \%-6 \%)$ of both groups' 
recommendations concerned finding ways to address language-related patient-provider communication barriers. For example, many patients suggested cultural training for all healthcare providers, sensitizing them particularly to differences between older and younger generation women in openness to discuss such sensitive subjects as sexual practices. Similarly, $12 \%$ and $15 \%$ of patients' and providers' recommendations, respectively, concerned addressing patients' specific needs, for example, cultural norms regarding the importance of female providers and understanding of family traditions and dietary practices. The greatest percentage of recommendations made by both providers $(63 \%)$ and patients (44\%) concerned addressing providers' lack of understanding of Muslim women's religious and cultural beliefs and practices. There was a notable difference in the percentage of recommendations made by each group regarding addressing patients' lack of understanding of disease processes, as well as suspicion/lack of trust in the healthcare system, including providers. Thirty-eight percent of patients' recommendations were in this category, in contrast to only $17 \%$ of providers' recommendations. To a large extent, the recommendations to address these challenges are directed toward modifications in provider behaviors and attitudes, clearly implying the importance of training of healthcare providers about the needs of this unique population.

Among religion-specific and culture-specific patient needs, those related to modesty, prayers and fasting, and family involvement in health management plans were noted particularly. For Muslim patients, respecting modesty needs for female patients, accommodating the needs related to daily prayers, and Ramadan fasting are among the most important. From a health policy standpoint, the most illustrative example of insensitivity by providers or the healthcare system is the failure to provide for Muslim women a female doctor when performing intimate physical examinations, such as breast and pelvic examinations. These examinations, when performed by a male provider, although considered standard in Western culture, are cruel violations of the Muslim female patient and her family that inflict personal humiliation and generate anger and resentment between Muslim patients and their healthcare providers. Our findings related to the modesty needs of Muslim women are consistent with previous studies. Muslim women, particularly those from immigrant backgrounds, find clinical encounters that involve examination of intimate body parts to be sources of anxiety and, therefore, major barriers to seeking and using care. Studies conducted in the United States, Canada, U.K., and Australia indicate that the failure of healthcare programs and providers to accommodate the religious and cultural beliefs of Muslim women, particularly needs for privacy and modesty, influences Muslim women's participation in cancer screening programs ${ }^{10,17,51,52}$ and antenatal care. ${ }^{14}$ In a Canadian study, women born in Asia, including Muslim women, were found to have the highest odds of never having been screened for cervical cancer, almost nine times more than Canadian-born women. ${ }^{53}$ Relevant to these findings, according to a British study, the risk of breast cancer among South Asian women in the U.K. differs according to their specific ethnic subgroup; Muslim women from India and Pakistan are almost twice as likely as their counterparts to develop breast cancer. ${ }^{54}$ Given the fact that the largest proportion of immigrant Muslims coming to the United States is from South Asia, there is an imminent need to tailor health services and programs to this patient group's religious needs and concerns.

Our study findings also indicate that providers are unclear about whether or not discussions concerning sexuality and reproductive health would be welcomed by Muslim women. The patient participants cautioned providers against thinking that all female Muslim patients would not be open to such discussions. Previous research indicates that when Muslim women's opinions about their care are solicited, they are enthusiastic and candid in discussing these highly sensitive topics. $^{17}$

The participants in our study also pointed out the need to avoid stereotyping. Immigrant Muslims in the United States come from many different regions and may have cultural beliefs and traditions specific to their countries of origin. Specific care areas considered particularly challenging by providers in our study included care for women with female circumcision and advising pregnant patients to balance their need to fast during the month of Ramadan with maintaining their health. Whereas fasting during Ramadan is universal to all Muslims, female circumcision is a cultural practice that predates Islam and has been adopted by some Muslims as a religious practice. Both, however, are excellent examples of where it is not only important to train providers to provide culturally appropriate care but also to educate and empower patients to better understand their religion; female circumcision is a harmful cultural practice, and women are exempt from fasting during pregnancy and lactation.

Provision of care that accommodates the values and beliefs of the patients and at the same time is evidence based requires a collaborative partnership between patients and providers. Immigrant patients cannot be expected to shun their religious beliefs and adopt the ways of their countries of adoption if those ways contradict their values. They can, however, be educated to prioritize their health needs and better understand how their religious beliefs may compromise their health. Providers, on the other hand, cannot be expected to have an in-depth understanding of each and every religion. At the very least, however, they can pause and listen to their patients and assure them that their individual beliefs and values are respected and will be accommodated to the extent possible. Simple changes can go a long way to gain patients' trust and engender comfort.

Although redesigning processes of care to enhance delivery of patient-centered care is a challenge and an ongoing dilemma for public and private policymakers, it is not unattainable. Small changes can go a long way. Maine Medical Center in Portland, Oregon, provides an excellent example of how a small system change can accommodate modesty needs of Muslim patients. When hospital providers and administrators learned about the embarrassment faced by Muslim women who had to wear the revealing standard issue hospital gown, hospital officials redesigned the gown to provide extra coverage for patients who want it. The new gown is longer and covers the legs, and extra material ensures that the patient's back remains covered. This simple change has far reaching consequences and proves that where there is a will to change, there certainly is a way. Before this change many Muslim women were so ashamed at the prospect of wearing the gown that they were cancelling visits. 


\section{Study limitations}

The primary limitations of this study are the small sample size and the distribution of participants. Additionally, the participants were women who had self-selected to participate in the conference on the subject of patient-centered care for Muslim women. The providers were $82 \%$ female and may not represent the general population of providers. The Muslim women in the study were small in number, mostly immigrants from Asian countries, and $>90 \%$ had college level or higher education. A truly random sample of providers and patients may not yield similar results.

Future studies with larger sample sizes would allow more in-depth exploration of specific issues and their association with demographic variables, such as education, religiosity, and country of origin. Larger-scale studies also would allow exploration of factors influencing quality of care as well as the impact of training interventions on provider competencies and patient satisfaction and outcomes.

\section{Implications}

The findings of this study underscore the significant gap that exists in the provision of culturally appropriate care for American Muslim women. There are several patient, provider, and health system-related factors that contribute to the challenges that immigrant Muslim women face in receiving quality healthcare. The lack of providers' understanding of Muslim women patients' religion and culture significantly impedes providers' ability to connect with their patients and provide them with care that meets their needs. Patients' perceptions about lack of accommodation of their religious and cultural beliefs can contribute to their reluctance in seeking care, which in turn may result in less than optimal use of health maintenance and preventive care services. In many cases, this means that patients will avoid seeing a healthcare provider until advanced stages of disease, ultimately resulting in poorer outcomes and higher costs.

In terms of finding solutions, some of the barriers, such as those due to language, access, and health insurance, are universal to underserved minorities or immigrant patients and more difficult and time intensive to tackle, as they involve system and policy changes. Better training and education of both patients and providers to address the barriers related to poor patient-physician communication, however, can and should be considered an immediate priority. It seems clear that patients, providers, the healthcare system, and society would benefit from tending to both patients' and providers' recognized needs for better understanding of and communication with each other. The need for training providers to provide patient-centered care resonates in the Institute of Medicine's (IOM) report, Health Professions Education: A Bridge to Quality, ${ }^{55}$ as well as in the New Model of Practice proposed by the Future of Family Medicine Project. ${ }^{56}$ Reducing the disconnect between what patients need and what they receive in the current healthcare system in the United States is certainly possible.

\section{Conclusions}

The increasing diversity of the United States population has implications for all aspects of healthcare delivery. ${ }^{2}$ The number of immigrants in the United States is on the rise, and the number of racial and ethnic minorities, now roughly one third of the U.S. population, is expected to become the majority by 2042, with the nation projected to be $54 \%$ minority by the year 2050. ${ }^{57}$ According to the IOM report, Unequal Treatment: Confronting Racial and Ethnic Disparities in Health Care, "racial and ethnic minorities tend to receive a lower quality of health care than non-minorities, even when access-related factors, such as patient's insurance status and income, are controlled." ${ }^{3}$

Muslims, the second largest religious group in the world, are spread geographically across the globe. They are the fastest growing religious group in the United States. Hence, it is important for all levels of healthcare providers to understand how to tailor care to meet the needs of this group. Before this study, there was little research on providers' perspectives on barriers to providing care to Muslim women or what their recommendations are for improving the quality of care provided to Muslim women.

The findings of this study confirm and expand previous work. The findings clearly suggest directions for improving the quality of care for Muslim women, and further, that there is strong accord about it between patients and providers. A particular strength of this study is that it includes the perspectives of physicians, nurses, and allied healthcare providers, indicating a multidisciplinary commitment to addressing the issues identified. Given that Islam is the religion followed by all Muslims, regardless of their country of origin and ethnic and cultural diversity, the common religious thread that ties this population together helps identify core religious needs of which providers should be aware. The finding that providers recognize their lack of understanding of this population's needs suggests that interventions to address this issue are likely to be well received. We postulate that the data and insights gleaned from this study can help guide additional research about how best to address the barriers that both providers and patients face in ensuring quality care for this unique and growing population. Further research about possible interventions and their effectiveness is indicated, and we suggest that we already know enough to take some first steps.

\section{Acknowledgments}

Funding for this research was, in part, by grant 1 R13 HS 15630-01 from the Agency for Healthcare Research and Quality. The views expressed in this article do not necessarily reflect the official policies of the Department of Health and Human Services, nor does mention of trade names, commercial practices, or organizations imply endorsement by the United States Government. The funding source had no involvement in the work carried out for this project, including study design and the collection, analysis, and interpretation of data and the writing of the article and the decision to submit it for publication. Findings of this research were presented at the 136th Annual Meeting of the American Public Health Association held at San Diego, California, October 2008.

\section{Disclosure Statement}

No competing financial interests exist for any of the authors. 


\section{References}

1. U.S. Department of Health and Human Services. Healthy people 2010, 2nd ed. With understanding and improving health and objectives for improving health. Washington, DC: U.S. Government Printing Office, 2000.

2. Institute of Medicine. Committee on Health Care in America. Crossing the quality chasm: A new health system for the 21st century. Washington, DC: National Academy Press, 2001.

3. Institute of Medicine. Unequal treatment: Confronting racial and ethnic disparities in health care. Washington, DC: National Academy Press, 2002.

4. Center for Health Professions. Toward culturally competent care: A toolbox for teaching communication strategies. San Francisco: University of California, San Francisco, 2002.

5. Saha S, Komaromy M, Koepsell TD, Bindman AB. Patientphysician racial concordance and the perceived quality and use of health care. Arch Intern Med 1999;159:997-1004.

6. Richardson LD. Patients' rights and professional responsibilities: The moral case for cultural competence. Mt Sinai J Med 1999;66:267-270.

7. Schwartz A, Hasnain M, Eiser AR, Lincoln E, Elstein AS. Patient-physician fit: An exploratory study of a multidimensional instrument. Med Decis Making 2006;26:122133.

8. Silow-Carroll S, Alteras T, Stepnick L. Patient-centered care for underserved populations. Economic and Social Research Institute. Washington, DC: The W.K. Kellogg Foundation, 2006. Available at www.esresearch.org/documents_06/ Overview.pdf

9. Hutchinson MK, Baqi-Aziz M. Nursing care of the childbearing Muslim family. J Obstet Gynecol Neonatal Nurs 1994;23:767-771.

10. Rajaram SS, Rashidi A. Asian-Islamic women and breast cancer screening: A sociocultural analysis. Women Health 1999;28:45-58.

11. Rashidi A, Rajaram SS. Middle Eastern Asian Islamic women and breast self-examination. Needs assessment. Cancer Nurs 2000;23:64-70.

12. Lawrence P, Rozmus C. Culturally sensitive care of the Muslim patient. J Transcult Nurs 20011;12:228-233.

13. Rashidi A, Rajaram SS. Culture care conflicts among AsianIslamic immigrant women in U.S. hospitals. Holist Nurs Pract 2001;16:55-64.

14. Tsianakas V, Liamputtong P. What women from an Islamic background in Australia say about care in pregnancy and prenatal testing. Midwifery 2002;18:25-34.

15. Roberts KS. Providing culturally sensitive care to the childbearing Islamic family. Adv Neonatal Care 2002;2:222228.

16. Roberts KS. Providing culturally sensitive care to the childbearing Islamic family: Part II. Adv Neonatal Care 2003;3: 250-255.

17. Matin M, LeBaron S. Attitudes toward cervical cancer screening among Muslim women: A pilot study. Women Health 2004;39:63-77.

18. Carter DJ, Rashidi A. East meets West: Integrating psychotherapy approaches for Muslim women. Holist Nurs Pract 2004;18:152-159.

19. Cortis JD. Meeting the needs of minority ethnic patients. J Adv Nurs 2004;48:51-58.

20. Davies K. Addressing the needs of an ethnic minority diabetic population. Br J Nurs 2006;15:516-519.
21. Miklancie MA. Caring for patients of diverse religious traditions: Islam, a way of life for Muslims. Home Healthc Nurse 2007;25:413-417.

22. Yosef AR. Health beliefs, practice, and priorities for health care of Arab Muslims in the United States. J Transcult Nurs 2008;19:284-291.

23. Numan FH. The Muslim population in the United States. Washington, DC: American Muslim Council, 1990.

24. The world almanac and book of facts. Mahwah, NJ: World Almanac Books, 2001:689.

25. Power P, Joseph N, Rhodes S. The new Islam. Newsweek 1998;131:34-37.

26. United States Department of State. Muslim communities: Patterns of Muslim immigration, 2005. Available at infousa.state.gov/education/overview/muslimlife/immigrat. htm

27. Ali YA. The meaning of the glorious Quran. 2:187. Cairo: Dar al-Kitab [translation modified], 1938.

28. Al-Qaradawi Y. The lawful and the prohibited in Islam. Indianapolis: American Trust Publications, 1960:148-236.

29. Doi AR. Shar'iah: The Islamic law. London: Ta Ha, 1984.

30. McDermott MY, Ahsan MM. The Muslim guide. Leicester: Islamic Foundation, 1993.

31. Badawi JA. Woman: Under the shade of Islam. Cairo: El-Falah, 1997.

32. Hasan S. Raising children in Islam. London: Al Quran Society, 1998.

33. Ebrahim AFM. Abortion, birth control and surrogate parenting: An Islamic perspective. Indianapolis: American Trust Publications, 1998.

34. Rahman F. Health and medicine in the Islamic tradition. Chicago: Kazi, 1998.

35. Azaiza F, Cohen M. Health beliefs and rates of breast cancer screening among Arab women. J Womens Health 2006;15: 520-530.

36. Dhami S, Sheikh A. The Muslim family: Predicament and promise. West J Med 2000;173:352-356.

37. Galanti GA. An introduction to cultural differences. West J Med 2000;172:335-336.

38. Galanti GA. American health care professionals should respect the traditions of other cultures. West J Med 2000;173: 356.

39. Aroian KJ. Immigrant women and their health. Annu Rev Nurs Res 2001;19:179-226.

40. Hasnain M, ed. Patient-centered health care for Muslim women in the United States. Conference Proceedings and Post Conference Evaluation Report, March 4-5, 2005. Chicago: University of Illinois at Chicago Press, 2006.

41. Duncan DF. Content analysis in health education research: An introduction to purposes and methods. Health Educ 1989;20:27-31.

42. Koenig HG, McCullough ME, Larson DB. Handbook of religion and health. Oxford, England: Oxford University Press, 2001.

43. Lee BY, Newberg AB. Religion and health: A review and critical analysis. Zygon 2005;40:443-468.

44. Winkelman M. Culture and health: Applying medical anthropology. San Francisco, CA: Jossey-Bass, John Wiley Sons, 2009

45. Laine C, Davidoff F. Patient-centered medicine. A professional evolution. JAMA 1996;275:152-156.

46. Carrillo JE, Green AR, Betancourt JR. Cross-cultural primary care: A patient-based approach. Ann Intern Med 1999;130: 829-834. 
47. Stewart M, Belle-Brown J, Weston WW, McWhinney IR, McWilliam, CL, Freeman T. Patient-centered medicine: Transforming the clinical method, 2nd ed. Abingdon, Oxford: Radcliffe Medical Press, 2003.

48. Betancourt JR. Cultural competence and medical education: Many names, many perspectives, one goal. Acad Med 2006;81:499-501.

49. Stewart MA. Effective physician-patient communication and health outcomes: A review. Can Med Assoc J 1995;152:14231433.

50. Stewart M, Brown JB, Donner A, et al. The impact of patientcentered care on outcomes. J Fam Pract 2000;49:796-804.

51. Bottorff JL, Johnson JL, Bhagat R, et al. Beliefs related to breast health practices: The perceptions of South Asian women living in Canada. Soc Sci Med 1998;47:2075-2085.

52. Underwood SM, Shaikha L, Bakr D. Veiled yet vulnerable. Breast cancer screening and the Muslim way of life. Cancer Pract 1999;7:285-290.

53. Lee J, Parsons GF, Gentleman JF. Falling short of Pap test guidelines. Reports, Statistics Canada 82-003 1998;10:9-19.

54. McCormack VA, Mangtani P, Bhakta D, McMichael AJ, dos Santos Silva I. Heterogeneity of breast cancer risk within the South Asian female population in England: A populationbased case-control study of first-generation migrants. Br J Cancer 2004;90:160-166.
55. Institute of Medicine. Greiner A, Knebel E. Committee on the Health Professions Summit. Health professions education: A bridge to quality. Washington, DC: National Academy Press, 2003.

56. Martin JC, Avant RF, Bowman MA, et al., for the Future of Family Medicine Project Leadership Committee. The Future of Family Medicine: A collaborative project of the family medicine community. Ann Fam Med 2004;2 (Suppl 1):S3-32.

57. United States Census Bureau News. U.S. Department of Commerce, Washington, DC. August 14, 2008. Available at www.census.gov/PressRelease/www/releases/archives/ population/012496.html

Address correspondence to: Memoona Hasnain, M.D., MHPE, Ph.D. Associate Professor $\mathcal{E}$ Director of Research Director, Patient-centered Medicine Scholars Program

Department of Family Medicine College of Medicine

University of Illinois at Chicago 1919 West Taylor Street, M/C 663 Chicago, IL 60612

E-mail: memoona@uic.edu 
